\title{
The Relationship between Nutritional Status and Early- and Mid-term Mortality of Geriatric Patients Admitted to the Emergency Internal Medicine Unit
}

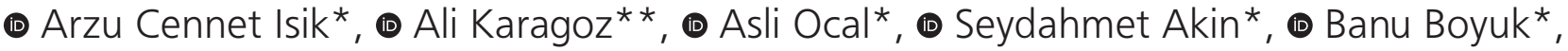 \\ - Ozcan Keskin* \\ *University of Health Sciences Turkey, Kartal Dr. Lutfi Kirdar City Hospital, Clinic of Internal Medicine, Istanbul, Turkey \\ ** University of Health Sciences Turkey, Kosuyolu Yuksek Ihtisas Training and Research Hospital, Clinic of Cardiology, Istanbul, Turkey
}

\section{Abstract}

\begin{abstract}
Aim: The need for bodily energy in the elderly may decrease due to physical activity limitations, while it may increase with the effects of the disease. The most common screening tool developed for the geriatric population is the Mini Nutritional Assessment, and lower scores are associated with higher mortality predictions. We aimed to correlate the nutritional status of patients admitted to the emergency department with mortality.
\end{abstract}

Materials and Method: Among the geriatric patients admitted to our emergency internal medicine unit between October 1, 2019, and March 1, 2020, 289 patients were included in this cross-sectional study. The Nutritional Risk Screening-2002 and Mini Nutritional Assessment tests were administered to all patients.

Results: The number of patients at risk of malnutrition was $49.4 \%(n=143)$. The median follow-up was 312 days for all patients, and the mortality rate was $42.5 \%(n=123)$ for all our patients, and $50.4 \%(n=72)$ of the patients who died were male. Diabetes was high in our geriatric patients, as in all age groups, and its effect on mortality was observed, and cancer patients had an almost three-fold higher malnutrition rate. Seventy patients were transferred from the internal medicine service to the intensive care unit, and 61 of these patients (87.14\%) died.

Conclusion: The Mini Nutritional Assessment is a non-complex and sensitive method that can be used to predict early and mid-term mortality in geriatric patients admitted to the emergency department.

Keywords: Malnutrition, nutritional assessment, nutritional surveys, emergency medicine

\section{Introduction}

The size of the geriatric age group, defined as 65 and over by the World Health Organization, is rapidly increasing in our country and all over the world. By 2050, it is estimated that the global elderly population, which was 900 million in 2015, will reach 2 billion, and in Turkey by 2080 , it is predicted to be $25.6 \%(1,2)$. This increase will result in rising healthcare service use and costs due to chronic diseases $(3,4)$.

The need for bodily energy in the elderly may decrease due to physical activity limitations, while it may increase with the effect of disease (5). Since malnutrition can occur not only in thin people but also in obese people, it is recommended that all geriatric patients be screened routinely for nutritional evaluation during hospital admissions and followed up regularly (3 months/yearly), depending on the patient's detected nutritional status.

The average minimum energy requirement of a geriatric patient is considered to be between 25 and $30 \mathrm{kcal} / \mathrm{kg}$ $(5,6)$. The most common screening tool developed for the geriatric population is the Mini Nutritional Assessment (MNA) (7). An observational study revealed that lower MNA scores are associated with higher mortality predictions (8). Another 5-year mortality study showed that the detection of malnutrition in hospitalized patients

\section{Address for Correspondence: Arzu Cennet Isik}

University of Health Sciences Turkey, Kartal Dr. Lutfi Kirdar City Hospital, Clinic of Internal Medicine,

Istanbul, Turkey

Phone: +90 5058174519 E-mail: arzukaracelik@gmail.com ORCID: orcid.org/0000-0001-9844-8599

Received: 16.10.2021 Accepted: 23.12.2021

Copyright 2022 by The Medical Bulletin of Istanbul Haseki Training and Research Hospital The Medical Bulletin of Haseki published by Galenos Yayinevi. 
with acute causes and different comorbidities effectively predicts all-cause mortality (9). In a study in Portugal, it was determined that the results of 456 patients who underwent short and long MNA tests were compatible, and even by adding two questions, the nutritional status could be better demonstrated (10).

However, the relationship of the MNA with early and mid-term mortality in emergency internal medicine referrals of the geriatric population has not been studied. This study aimed to evaluate the effect of the nutritional status of geriatric patients receiving inpatient treatment in emergency internal medicine clinics on early and mid-term mortality.

\section{Methods}

\section{Study Design}

The ethics committee of University of Health Sciences Turkey, Kartal Dr. Lutfi Kirdar City Hospital approved the study on 06.12.2019 with the number 2019/514/167/23, and it was performed following the 1964 Declaration of Helsinki and its later amendments. An informed consent form was approved by all patients. Among the geriatric patients admitted to our emergency internal medicine unit between October 1, 2019, and March 1, 2020, 289 hospitalized patients were prospectively included in the study. Clinical and laboratory information was obtained from electronic records, and the patients were evaluated with the MNA following the nutrition risk screening in 2002 (NRS-2002) (11). Body mass index (BMI) is defined as a person's weight in kilograms divided by the square of his height in meters $\left(\mathrm{kg} / \mathrm{m}^{2}\right)$. A BMI of less than 18.5 means a person is underweight.

A BMI of between 18.5 and 24.9 is ideal. A BMI of between 25 and 29.9 is considered overweight, and over 30 is obese. The detailed study inclusion and exclusion criteria are indicated in Figure 1.

\section{Nutritional Assessment}

NRS-2002 aims to identify people who will benefit from nutritional therapy due to increased nutritional needs resulting from malnutrition and/or disease. The screening form includes an initial scan and a final scan. A final screening is performed if the answer to any of the four questions in the first screening is "yes". Patients with a total score of three or more are considered to be at nutritional risk.

MNA was developed as a reliable screening test to determine whether nutrition is adequate in aged people (7). With questions and anthropometric measurements, the nutritional status of patients can be easily estimated even without laboratory data (12). Although the parameters used are not crucial for diagnosis, they are generally essential for follow-up. The first part consists of six questions and is a quick screening test. The total score is obtained by asking in the second part an additional 12 questions of those who scored lower in the first part. A total score of 23.5 and above is considered normal nutritional status, a score between 17 and 23 is a risk of malnutrition, and a score $<17$ is considered malnutrition. There is not yet a specific laboratory test that can be used to diagnose malnutrition.

The NRS-2002 test and the first part of the MNA were administered to all patients. The long MNA was not applied to those with adequate nutrition, but by evaluating the scores from the first part, those who did not have sufficient nutrition were evaluated with the long MNA.

Chronic disease and malignancy diagnoses of the patients were determined, and the NRS and MNA tests were performed. As per the MNA score, patients with malnutrition and those at risk of malnutrition were evaluated as having nutritional deficiencies, and their nutrition was arranged according to their nutritional status. Within one year after discharge, follow-up and mortality data were provided using hospital and telephone visits or a national registry system.

\section{Statistical Analysis}

Numerical variables are represented by median and interquartile-ranges $\left(25^{\text {th }}-75^{\text {th }}\right)$, Wilcoxon ranksum test used for the comparisons. For the discrete data, frequencies and absolute numbers are given as frequencies. For comparison, Pearson chi-squared was used. For the correlation analysis of numerical variables, the Spearman test was used.

Outcome variable: All-cause mortality until one year of follow-up.

Multivariable Cox regression was used to find allcause mortality predictors. The plausible predictors of the multivariable regression model were selected according to the literature, and our main variable (MNA). The KaplanMeier curve and the log-rank test were used for the group comparison. A two-tailed p-value $<0.05$ was set as the significance level. The statistical analyses were performed using R version 4.01 software (Vienna, Austria) with the "rms", "survival", "ggplot", and "desctool" packages.

\section{Results}

A total of 289 elderly patients who applied to emergency services were included in our study, of whom $48.4 \% \quad(n=140)$. The prevalence of malnutrition and patients at risk of malnutrition was $49.4 \%(n=143)$, while nutritional deficiency was found in $49.6 \%(n=71)$ of this group. The comorbid diseases found were hypertension (72.2\%; $\mathrm{n}=203)$, ischemic heart disease (50.8\%; $\mathrm{n}=147)$, diabetes mellitus (35.2\%; $\mathrm{n}=102$ ), 
chronic renal failure (32.8\%; $n=95)$, malignancy $(25.2 \%$; $n=73)$, neuropsychiatric disease $(22.8 \% ; n=66)$, chronic obstructive pulmonary disease $(19.03 \% ; n=55)$, and chronic liver disease (9.6\%; $\mathrm{n}=28$ ) (Table 1). In relation to the reasons for hospitalization, $11.1 \% \quad(n=32)$ of the patients were hospitalized for gastrointestinal system diseases, $14.9 \% \quad(n=43)$ decompensated heart failure, 26\% $(n=75)$ renal diseases, 5.5\% $(n=16)$ electrolyte imbalance and diabetic coma, 9.3\% ( $n=27)$ hematological and rheumatologic diseases, 18\% ( $n=52)$ upper gastrointestinal bleeding and inflammatory bowel diseases, and $15.2 \%(n=44)$ supportive treatment.

The median follow-up was 312 days for all patients, and the mortality rate was $42.5 \%(n=123)$ for all our patients, and $50.4 \%(n=72)$ of the patients who died were male. Seventy patients were transferred from the internal medicine service to the intensive care unit (ICU), and 61 of these patients $(87.14 \%)$ died.

When the MNA scores were evaluated, mortality occurred in $67(72.8 \%)$ of 92 people with a score of $<17$ indicating malnutrition, and in $25(49.01 \%)$ of the 51 people at risk of malnutrition with a score between 17 and 23. These two patient groups were considered to have a nutritional deficiency. The number of patients in the group with good nutrition, i.e., with a score of 23.5 and above, was 146 (50.5\%), and 31 (21.2\%) of them died. $\mathrm{BMI}$ results included six people (4.2\%) with a $\mathrm{BMI}<18.5$ $\mathrm{kg} / \mathrm{m}^{2}$ and 81 people (56.6\%) with a BMl in the range of $18.5-25 \mathrm{~kg} / \mathrm{m}^{2}$, and the mean BMI was lower in the deceased group with a range of $24.2(22-26)(p<0.001)$ (Table 2).

Univariable Cox proportional regression analysis showed that the MNA, NRS, C-reactive protein, BMI, and albumin were associated with mortality (Table 3). Multivariable Cox regression analysis revealed that the MNA, the NRS, and albumin were associated with mortality 0 vs. 2, [hazard ratio (HR) $2.6495 \%$ confidence interval (Cl) 1.56-4.45], 0 vs. 1 [HR $2.11(95 \% \mathrm{Cl} 1.22-$ 3.68)], 0 vs. 2 [HR $1.56(95 \% \mathrm{Cl} 1-2.44)], 0$ vs. 1 [HR $0.54(95 \% \mathrm{Cl} 0.38-0.78)]$ respectively. The other results are presented in Table 3.

The Kaplan-Meier curve showed higher mortality in the score $<17$ and score between 17 and 23 groups when compared to the score of 23.5 and above groups, with a p-value $<0.0001$ in the log-rank test (Figure 2).

\begin{tabular}{|c|c|c|c|}
\hline Variables & Alive $(n=166)$ & Deceased $(n=123)$ & p-value \\
\hline Age & $75(70-81)$ & $78(71-84.5)$ & 0.055 \\
\hline Gender n, (\%) (female) & $72(43.4)$ & $68(55.3)$ & $0.04^{\#}$ \\
\hline Diabetes mellitus $n,(\%)$ & $60(36.1)$ & $42(34.1)$ & 0.72 \\
\hline Hypertension n, (\%) & $131(78.9)$ & $72(62.6)$ & $0.002^{\#}$ \\
\hline Coronary artery disease $n,(\%)$ & $86(51.8)$ & $61(49.6)$ & 0.71 \\
\hline Chronic obstructive pulmonary disease $n,(\%)$ & $30(18.1)$ & $25(20.3)$ & 0.63 \\
\hline Malignancy n, (\%) & $22(13.3)$ & $51(41.5)$ & $<0.001^{\#}$ \\
\hline Chronic kidney disease $n,(\%)$ & $46(27.7)$ & $49(38.9)$ & $0.03^{\#}$ \\
\hline Chronic liver disease $n,(\%)$ & $11(6.6)$ & $17(13.8)$ & $0.004^{\#}$ \\
\hline Neuropsychiatric disorders $n,(\%)$ & $34(20.5)$ & $32(26.0)$ & 0.26 \\
\hline Albumin & $3.2(2.9-3.68)$ & $2.7(2.4-3.05)$ & $<0.001^{*}$ \\
\hline C-reactive protein & $20.3(4.22-76)$ & $47.7(13.9-101)$ & $<0.001^{*}$ \\
\hline Lymphocyte & $1300(900-1700)$ & $900(650-1400)$ & $<0.001^{*}$ \\
\hline Intensive care unit stay n, (\%) & $9(5.4)$ & $61(49.6)$ & $<0.001^{*}$ \\
\hline Total cholesterol & $168(136-205)$ & $142(124-184)$ & $<0.001^{*}$ \\
\hline $\mathrm{HbA} 1 \mathrm{c}$ & $6(5.6-6.57)$ & $5.7(5.2-6.65)$ & 0.08 \\
\hline Follow-up duration & $356(319-396)$ & $48(17-231)$ & $<0.001^{*}$ \\
\hline Body mass index & $25.4(24.2-26.9)$ & $24.2(22-26)$ & $<0.001^{*}$ \\
\hline Nutritional risk screening $n,(\%)$ & $22(13.3)$ & $56(45.9)$ & $<0.001^{*}$ \\
\hline \multicolumn{4}{|l|}{ Mini nutritional assessment $\mathrm{n},(\%)$} \\
\hline $\begin{array}{l}0(<17) \\
1(17-23) \\
2(>23.5)\end{array}$ & $\begin{array}{l}25(15.1) \\
26(15.7) \\
115(69.3)\end{array}$ & $\begin{array}{l}67(54.5) \\
25(15.3) \\
31(25.2)\end{array}$ & $<0.001^{\#}$ \\
\hline
\end{tabular}




\section{Discussion}

Our study showed that the MNA, which calculates malnutrition status, was independently associated with early and mid-term mortality and. In our study, in which the nutrition and survival of 289 geriatric inpatients admitted to the emergency department and followed up were evaluated, nutritional status was a strong determinant of survival. At their 12-month follow-up, mortality was not observed in 51 (35.6\%) of 143 people (49.4\%) with malnutrition and malnutrition risk. All-cause mortality was high in our patients with nutritional deficiency and malignancy $(p<0.001)$. Mortality occurred in $61(87.1 \%)$ of our patients admitted to the ICU. When concomitant diseases were evaluated, hypertension was the most common, and liver diseases were seen the least.

In a randomized controlled study in Ireland, when 353 elderly patients admitted to the emergency room were evaluated with the MNA test, it was found that more than one third were at risk of malnutrition or malnutrition. This was associated with a longer stay in the emergency department, a decrease in functional capacity and quality of life, and an increased risk of hospitalization. Patients defined as malnourished in the emergency department were more than four times more likely to report a decline in quality of life and mortality

\begin{tabular}{|c|c|c|c|}
\hline & MNA $(\geq 23.5)$ & MNA $(\leq 23.5)$ & p-value \\
\hline \multicolumn{4}{|l|}{ Age } \\
\hline $65-74$ years & $68(46.6 \%)$ & $58(40.6 \%)$ & \multirow{3}{*}{0.137} \\
\hline $75-84$ years & $55(37.7 \%)$ & $49(34.3 \%)$ & \\
\hline$\geq 85$ years & $23(15.8 \%)$ & $36(25.2 \%)$ & \\
\hline \multicolumn{4}{|l|}{ Body mass index } \\
\hline$<18.5$ & $0(0 \%)$ & $6(4.2 \%)$ & \multirow{4}{*}{$<0.001^{\#}$} \\
\hline $19-24.9$ & $30(20.5 \%)$ & $81(56.6 \%)$ & \\
\hline $25-29.9$ & $102(69.9 \%)$ & $51(35.7 \%)$ & \\
\hline$>30$ & $14(9.6 \%)$ & $5(3.5 \%)$ & \\
\hline Malignancy & $29(19.9 \%)$ & $44(30.8 \%)$ & $0.03^{\#}$ \\
\hline Gender (female) & $69(47.3 \%)$ & $71(49.7 \%)$ & 0.68 \\
\hline \multicolumn{4}{|c|}{$\begin{array}{l}\text { "Categoric comparison made with chi-square, MNA }(\geq 23.5) \text { group } \\
\text { was higher body mass index than MNA }(\leq 23.5) p<0.001 \text {. } \\
\text { MNA: Mini Nutritional Assessment }\end{array}$} \\
\hline
\end{tabular}

was higher than patients defined as having a normal nutritional status (13).

Malnutrition has emerged as a major problem among the aged. Different mechanisms, such as gastrointestinal and endocrine system disorders, decreased appetite, loss of taste and smell, and malnutrition due to both disease states and psychosocial factors, are involved in the

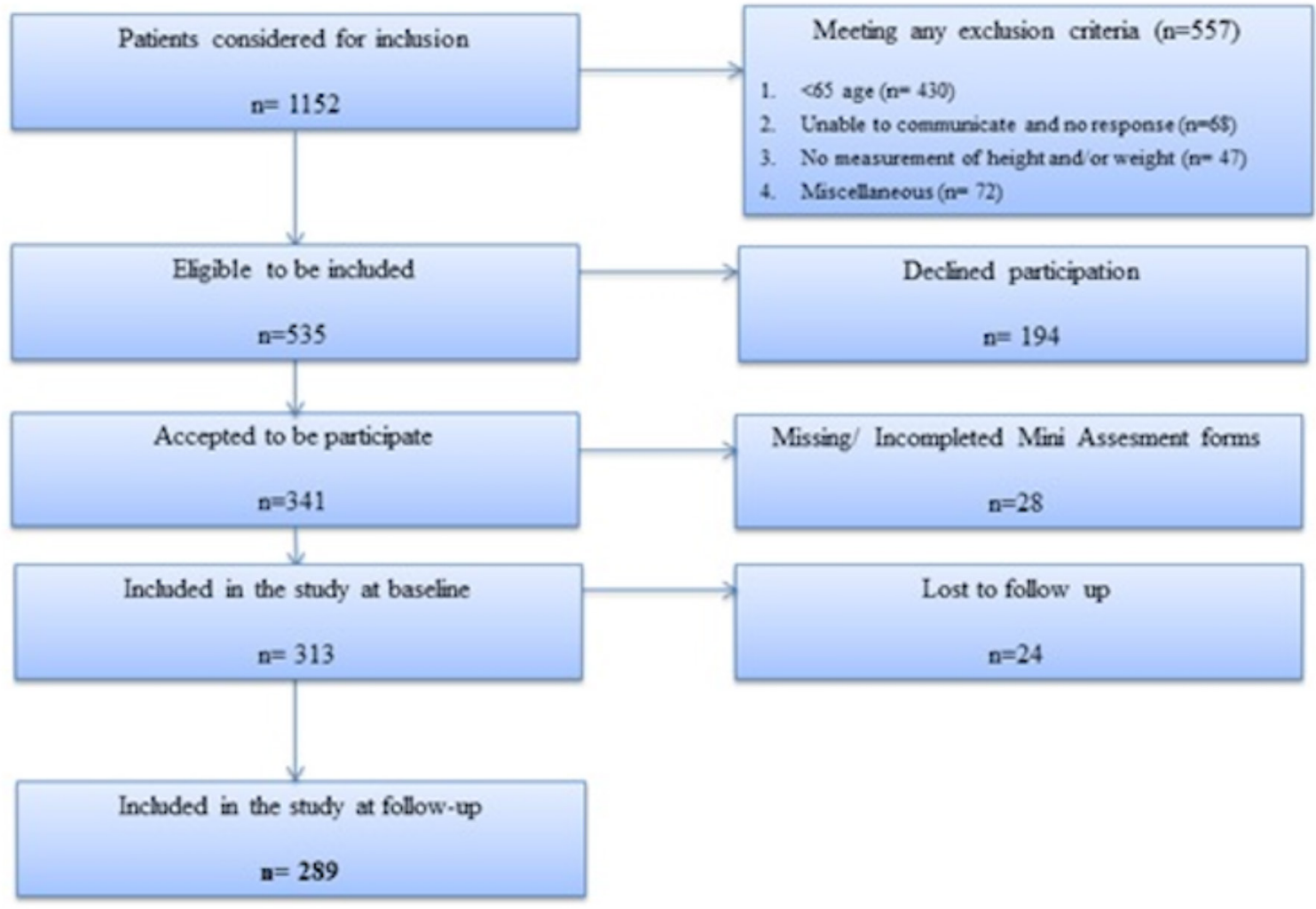

Figure 1. Flow chart of inclusion and exclusion criteria 


\begin{tabular}{|c|c|c|c|c|}
\hline Variables & $\begin{array}{l}\text { Univariate HR, } \\
\mathrm{Cl} 95 \%\end{array}$ & p-value & Multivariate $\mathrm{HR}, \mathrm{Cl} 95 \%$ & p-value \\
\hline Age (per 1-year increase) & $1.02(1.00-1.05)$ & 0.029 & $1.00(0.98-1.03)$ & 0.679 \\
\hline Gender (male reference) & $1.41(0.919-2.01)$ & 0.058 & $1.67(1.13-2.47)$ & $0.01^{\S}$ \\
\hline Diabetes mellitus & $1.00(0.69-1.45)$ & 0.98 & $0.94(0.67-1.47)$ & 0.796 \\
\hline Hypertension & $0.608(0.42-0.87)$ & 0.006 & $0.69(0.43-1.09)$ & 0.111 \\
\hline Coronary artery disease & $0.91(0.64-1.30)$ & 0.600 & $1.16(0.76-1.77)$ & 0.505 \\
\hline COPD & $1.10(0.71-1.71)$ & 0.675 & $1.25(0.79-1.97)$ & 0.348 \\
\hline Malignancy & $2.51(1.75-3.60)$ & $<0.001$ & $2.46(1.62-3.73)$ & $<0.001^{\S}$ \\
\hline Chronic kidney disease & $1.58(1.10-2.27)$ & $<0.001$ & $1.94(1.28-2.94)$ & $0.002^{\S}$ \\
\hline Chronic liver disease & $1.77(1.06-2.95)$ & 0.03 & $1.61(0.93-2.78)$ & 0.091 \\
\hline Neuropsychiatric disorders & $1.43(0.96-2.14)$ & 0.082 & $1.49(0.96-2.29)$ & 0.072 \\
\hline $\begin{array}{l}\text { MNA } 0 \text { vs. } 2^{*} \\
\text { MNA } 1 \text { vs. } 2^{*}\end{array}$ & $\begin{array}{l}5.39(3.51-8.28) \\
3.03(1.79-5.14)\end{array}$ & $\begin{array}{l}<0.001 \\
<0.001\end{array}$ & $\begin{array}{l}2.64(1.56-4.45) \\
2.11(1.22-3.68)\end{array}$ & $\begin{array}{l}<0.001^{\S} \\
0.008^{\S}\end{array}$ \\
\hline NRS-2002 & $3.52(2.46-5.04)$ & $<0.001$ & $1.56(1.001-2.44)$ & $0.049 \S$ \\
\hline CRP (per 1 unit increase) & $1.001(1.000-1.002)$ & 0.03 & $1.00(0.99-1.001)$ & 0.42 \\
\hline Albumin (per 1 unit increase) & $0.39(0.29-0.52)$ & 0.005 & $0.54(0.38-0.78)$ & $0.001^{\S}$ \\
\hline BMI (per 1 unit increase) & $0.83(0.78-0.89)$ & $<0.001$ & $0.86(0.80-0.93)$ & $<0.001^{\S}$ \\
\hline 25-OH D3 (per 1 unit increase) & $1.001(0.99-1.01)$ & 0.70 & $1.00(0.99-1.01)$ & 0.34 \\
\hline \multicolumn{5}{|c|}{$\begin{array}{l}\text { *MNA 0: Score <17, MNA 1: 18-23, MNA 2: }>23.5 \\
\text { `Cox regression analysis significant result. Both MNA } 0 \text { and } 1 \text { associated worse outcome than MNA 2; }[2.64(1.56-4.45) p<0.001,2.11(1.22-3.68) p=0.008 \text { respectively]. } \\
\text { COPD: Chronic obstructive pulmonary disease, CRP: C-reactive protein, BMI: Body mass index, MNA: Mini Nutritional Assessment, NRS-2002: Nutritional Risk Screening-2002, } \\
\text { Cl: Confidence interval, HR: Hazard ratio }\end{array}$} \\
\hline
\end{tabular}

\section{Strata + MNA $2+$ MNA0_1}

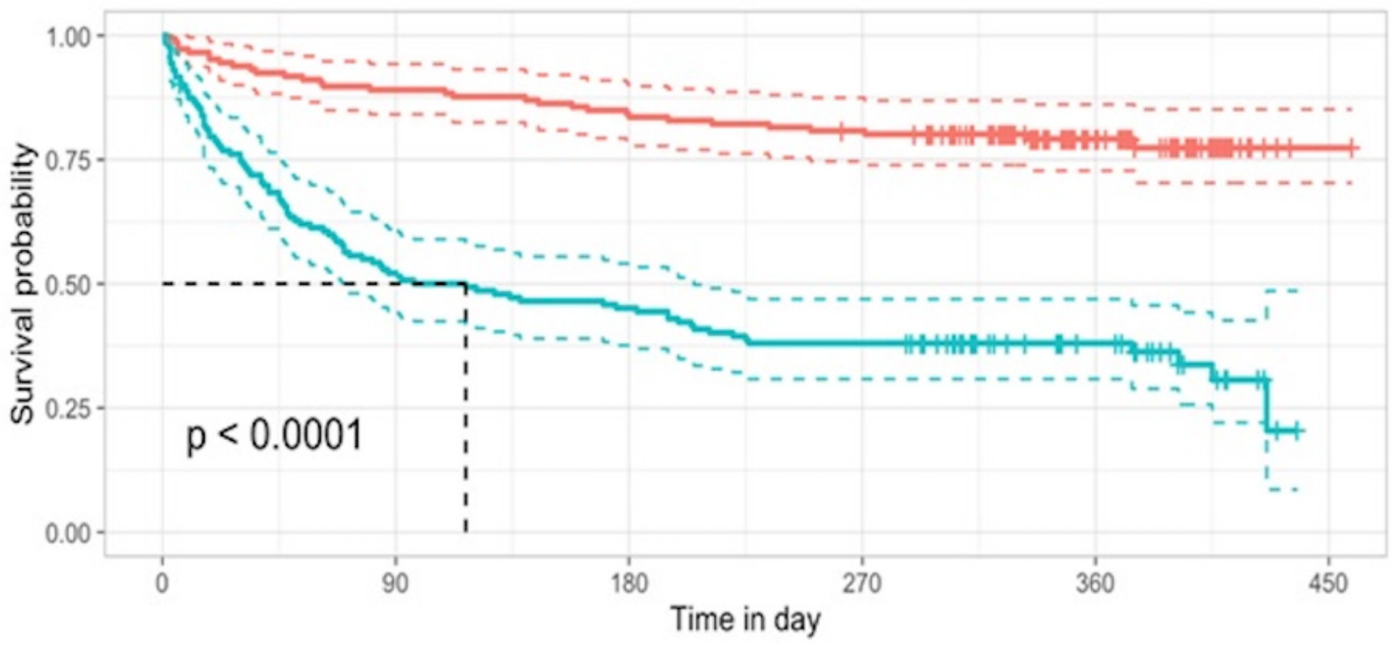

Number at risk: $\mathrm{n}(\%)$

\begin{tabular}{|c|c|c|c|c|c|}
\hline $\begin{array}{l}\frac{\pi}{\omega}=46(100) \\
\omega=43(100)\end{array}$ & $\begin{array}{c}130(89) \\
74(52)\end{array}$ & $\begin{array}{l}123(84) \\
64(45)\end{array}$ & $\begin{array}{c}117(80) \\
54(38)\end{array}$ & $\begin{array}{l}60(41) \\
25(17)\end{array}$ & $\begin{array}{l}1(1) \\
0(0)\end{array}$ \\
\hline 0 & 90 & 180 & 270 & 360 & 450 \\
\hline
\end{tabular}

Figure 2. Kaplan-Meier curve comparison between MNA 2 and MNA 0-1 MNA: Mini Nutritional Assessment 
development of malnutrition in the elderly (14). Therefore, it is crucial to support a diet containing food and liquid with adequate and appropriate nutrition to prevent and treat malnutrition.

Obesity is an increasing problem in the elderly as well as the general population, and it currently affects $18 \%$ to $30 \%$ of the world's population aged 65 and over (14). The mean BMI of our patients who did not die was 25.4 $(24.2-26.9) \mathrm{kg} / \mathrm{m}^{2}$, and as the BMI increased to be in the range of 25-30, a lower risk of death was found compared to the elderly patients with a BMI in the normal range.

In a study conducted by Kaiser et al. (15), the MNA was recommended as a screening test to be used as the basis of nutritional assessment, especially due to its predictive characteristics for early detection and assessment of malnutrition risk in the elderly population and the regulation of nutrition. In their study, the malnutrition rate in the elderly in the community was $5.8 \%, 13.8 \%$ in those living in nursing homes, and $38.7 \%$ in hospitalized patients (15). The malnutrition rate was significantly high in our study, with a value of $49.4 \%$; therefore, the elderly population should be evaluated in terms of nutrition and those with malnutrition or at risk of malnutrition should be monitored periodically.

Our study showed a diabetes prevalence of $35.2 \%$ and a $41.17 \%$ in mortal cases, which is higher than our country's data. In the Turkish Diabetes Epidemiology Study, one of the largest data-based studies, the prevalence of type 2 diabetes was found to be $7.2 \%$ in individuals aged 20-60, while it was 20\% in individuals over 60 years old (16). Diabetes was high in our geriatric patients, as in all age groups, and its effect on mortality was observed. Malnutrition is considered a hallmark of advanced malignant disease in cancer patients who have an almost three times higher rate of malnutrition (17). Anorexiacachexia is seen in cancer patients. This situation occurs as a result of complaints such as nausea, vomiting, and early satiety and leads to results such as poor quality of life, poor prognosis, and loss of functional status. In our study, 30.8\% ( $n=44)$ of the cancer patients had low MNA scores. A recent study found the malnutrition status of geriatric patients followed in the ICU affected the duration of hospital stay, post-discharge care, and mortality. In the study, 331 geriatric patients were followed up, and their nutrition scores with the NRS and the MNA were found to be in the range of $23-34 \%$ (18). In our study, mortality $(87.14 \%)$ was high in those transferred to the ICU, and $32(52.4 \%)$ of these patients had nutritional deficiencies.

Considering the data in our study, age, comorbidities, $\mathrm{BMI}$, and mortality were associated with malnutrition. Various physiological and psychological changes in advanced age lead to decreased hunger, insufficient food intake, metabolic inefficiency, and impaired nutrition. As demonstrated in our study, malnutrition associated with internal emergency diseases is a significant risk factor, especially in terms of mortality. Therefore, it should be kept in mind as an additional evaluation parameter in the elderly population.

\section{Study Limitations}

The limitation of the study is the data from a singlecenter analysis, resulting in the regression analysis's low causal inference. Investigations from different centers are needed to confirm the data. Our study's strength consists of geriatric patients who were followed up, admitted to the tertiary referral and oncology center's emergency room and hospitalized.

\section{Conclusion}

Nutritional status in geriatric patients admitted to the emergency internal medicine service was associated with mortality for up to one year regardless of other causes, and age, comorbidities, BMI, and mortality were associated with malnutrition. The MNA is a non-complex and sensitive method that can be used to predict early and mid-term mortality in geriatric patients admitted to the emergency department.

\section{Ethics}

Ethics Committee Approval: The ethics committee of University of Health Sciences Turkey, Kartal Dr. Lutfi Kirdar City Hospital approved the study on 06.12.2019 with the number 2019/514/167/23.

Informed Consent: An informed consent form was approved by all patients.

\section{Authorship Contributions}

Concept: A.C.I., S.A., Design: B.B., O.K., Data Collection or Processing: A.C.I., A.K., Analysis or Interpretation: A.C.I., A.K., Literature Research: A.C.I., A.K., Writing: A.C.I., A.K., S.A. A.O.

Conflict of Interest: No conflict of interest was declared by the authors.

Financial Disclosure: The authors declared that this study received no financial support.

\section{References}

1. Türkiye İstatistik Enstitüsü. İstatistiklerle Yaşlılar, 2020 [Internet]. 18.03.2021. 2021. p. 1-10. Available from: https://data.tuik.gov.tr/Bulten/Index? p=IstatistiklerleYaslilar-2020-37227

2. World Health Organization. Ageing and health [Internet]. 2018. Available from: https://www.who.int/news-room/factsheets/detail/ageing-and-health

3. Centers for Disease Control and Prevention (CDC). Trends in aging-United States and worldwide. MMWR Morb Mortal Wkly Rep 2003;52:101-6. 
4. Burak $C$, Süleymanoğlu $M$, Gümüşdağ $A$, et al. The effect of nutritional status on long-term mortality in very elderly patients with st segment elevation myocardial infarction. Turkish Journal Geriatris 2021;24:87-94.

5. Gaillard C, Alix E, Sallé A, Berrut G, Ritz P. Energy requirements in frail elderly people: a review of the literature. Clin Nutr 2007;26:16-24.

6. Visvanathan R. Under-nutrition in older people: a serious and growing global problem! J Postgrad Med 2003;49:352-60.

7. Vellas B, Guigoz $Y$, Garry PJ, et al. The mini nutritional assessment (MNA) and its use in grading the nutritional state of elderly patients. Nutrition 1999;15:116-22.

8. Sheean PM, Peterson SJ, Chen Y, Liu D, Lateef O, Braunschweig CA. Utilizing multiple methods to classify malnutrition among elderly patients admitted to the medical and surgical intensive care units (ICU). Clin Nutr 2013;32:752-7.

9. Balci C, Bolayir B, Eşme M, et al. Comparison of the Efficacy of the Global Leadership Initiative on Malnutrition Criteria, Subjective Global Assessment, and Nutrition Risk Screening 2002 in Diagnosing Malnutrition and Predicting 5-Year Mortality in Patients Hospitalized for Acute Illnesse. JPEN J Parenter Enter Nutr 2021;45:1172-80.

10. Poínhos R, Oliveira BMPM, Sorokina A, Franchini B, Afonso C, de Almeida MDV. An extended version of the MNA-SF increases sensitivity in identifying malnutrition among community living older adults. Results from the PRONUTRISENIOR project. Clin Nutr ESPEN 2021;46:167-72.
11. Kondrup J, Allison SP, Elia M, Vellas B, Plauth M; Educational and Clinical Practice Committee, European Society of Parenteral and Enteral Nutrition (ESPEN). ESPEN guidelines for nutrition screening 2002. Clin Nutr 2003;22:415-21.

12. Buscemi S, Batsis JA, Parrinello G, et al. Nutritional predictors of mortality after discharge in elderly patients on a medical ward. Eur J Clin Invest 2016;46:609-18.

13. Griffin A, O'Neill A, O'Connor M, Ryan D, Tierney A, Galvin $R$. The prevalence of malnutrition and impact on patient outcomes among older adults presenting at an Irish emergency department: a secondary analysis of the OPTIMEND trial. BMC Geriatr 2020;20:455.

14. Porter Starr KN, McDonald SR, Weidner JA, Bales CW. Challenges in the Management of Geriatric Obesity in High Risk Populations. Nutrients 2016;8:262.

15. Kaiser MJ, Bauer JM, Rämsch C, et al. Frequency of malnutrition in older adults: a multinational perspective using the mini nutritional assessment. J Am Geriatr Soc 2010;58:1734-8.

16. Satman I, Omer B, Tutuncu Y, et al. Twelve-year trends in the prevalence and risk factors of diabetes and prediabetes in Turkish adults. Eur J Epidemiol 2013;28:169-80.

17. Ravasco P, Monteiro-Grillo I, Vidal PM, Camilo ME. Nutritional deterioration in cancer: the role of disease and diet. Clin Oncol (R Coll Radiol) 2003;15:443-50.

18. Gündüz $E$, Eskin $F$, Gündüz $M$, et al. Malnutrition in Community-Dwelling Elderly in Turkey: A Multicenter, CrossSectional Study. Med Sci Monit 2015;21:2750-6. 